\title{
Effect of bimodal pores on sintering and residual stresses of YSZ membranes prepared by non-solvent induced phase separation method
}

DOI:

10.1016/j.jeurceramsoc.2018.12.037

\section{Document Version}

Accepted author manuscript

Link to publication record in Manchester Research Explorer

Citation for published version (APA):

Cai, H., Guo, F., Wang, G., Wang, X., Zhao, X., \& Xiao, P. (2018). Effect of bimodal pores on sintering and residual stresses of YSZ membranes prepared by non-solvent induced phase separation method. Journal of the European Ceramic Society. https://doi.org/10.1016/j.jeurceramsoc.2018.12.037

\section{Published in:}

Journal of the European Ceramic Society

\section{Citing this paper}

Please note that where the full-text provided on Manchester Research Explorer is the Author Accepted Manuscript or Proof version this may differ from the final Published version. If citing, it is advised that you check and use the publisher's definitive version.

\section{General rights}

Copyright and moral rights for the publications made accessible in the Research Explorer are retained by the authors and/or other copyright owners and it is a condition of accessing publications that users recognise and abide by the legal requirements associated with these rights.

\section{Takedown policy}

If you believe that this document breaches copyright please refer to the University of Manchester's Takedown Procedures [http://man.ac.uk/04Y6Bo] or contact uml.scholarlycommunications@manchester.ac.uk providing relevant details, so we can investigate your claim.

\section{OPEN ACCESS}




\section{Effect of bimodal pores on sintering and residual stresses of YSZ membranes}

prepared by non-solvent induced phase separation method

Huangyue Cai

School of materials science and engineering, Shanghai Jiao Tong University,

Shanghai 200240, China

Fangwei Guo*

School of materials science and engineering, Shanghai Jiao Tong University,

Shanghai 200240, China

Guowei Wang

China Nuclear Power Engineering \&Technology Co. Ltd., Shanghai 200240, China

Xin Wang

Solar Space Co. Ltd., Xuzhou 221699, China

Xiaofeng Zhao

School of materials science and engineering, Shanghai Jiao Tong University,

Shanghai 200240, China

Ping Xiao

School of Materials, University of Manchester, Manchester M13 9PL, United

Kingdom

\footnotetext{
* Corresponding author: Fangwei Guo

Email: fwguo2014@sjitu.edu.cn; Tel: +86-21-54742561; Fax: +86-21-54742561
} 


\begin{abstract}
Densification mismatch and residual stresses of tri-layered yttria-stabilized zirconia (YSZ) membranes prepared by a non-solvent induced phase separation (NIPS) method were investigated. The tri-layered membrane consisted of sponge-like structures and finger-like voids in macroscale. The densification of the two structures were characterized to elaborate their contribution to the densification mismatch, which led to residual stresses of hundreds of megapascal retained in the sintered membranes. The profile of residual stress suggested that it was related to the strain rate mismatch within the NIPS membranes, which was further quantified with an in-situ monitored camber evolution.
\end{abstract}

Keywords: non-solvent induced phase separation; tri-layered ceramic membranes; densification mismatch; residual stress; yttria-stabilized zirconia. 


\section{Introduction}

Ceramic membranes fabricated by the non-solvent induced phase separation (NIPS) method have potentials in many applications such as solid oxide fuel cells, water purification and catalytic reactor, because of the stability of ceramics in harsh environment and the unique structure of NIPS membranes [1-4]. NIPS membranes typically show a tri-layered structure with a sponge-like layer (SLL) supported on a finger-like voids layer (FVL), and the top surface is covered with a dense skin layer. The skin layer and/or the SLL can perform as selective layers and the FVL as a supported layer [5]. Sintering is always required to achieve a proper mechanical strength for the ceramic membranes, which is also one of the most critical steps because many defects including residual stresses, cracks, delamination and shape distortion, could be generated from the densification mismatch between the constituent layers [68]. These undesired defects could weaken the sealing and degrade the mechanical performance of the NIPS membranes in service.

The densification mismatch of multilayered structures is usually attributed to the different densification kinetics of different materials and/or the variation of green density. Many researches have been done to analyze the distortion kinetics of the multilayered systems and the associated sintering mismatch stresses using isotropic constitutive laws [9-13]. The theoretical models developed require constitutive parameters (eg, uniaxial viscosity) of each constituent layer for the calculation of densification strain rate mismatch and the consequent sintering mismatch stresses. However, for NIPS membranes, there is no distinct interface between the constituent 
layers, and the finger-like voids featured a hierarchical structure with structural gradient. In this case only the constituent parameters of the whole NIPS membrane can be measured instead of the individual layers by the thermal mechanical analysis (TMA). While the constituent parameters of the entire multilayered membrane cannot be used to explain the densification mismatch. Although many theoretical approaches have been proposed for the computation of viscosity, there is no one can be directly used in this study [14]. Thus, this work seeks to understand the mechanism of densification mismatch which occurs during the sintering of NIPS membranes by evaluating the microstructure and distortion evolution.

During the sintering of multilayered systems, it was recognized that internal residual stresses can be generated $[8,15]$. These stresses are formed due to two primary contributing factors: the difference in the densification rate of different constituent powders into a ceramic body and the difference in the thermal expansion coefficient (CTE) of the densified ceramic, which arises during cooling from the sintering temperature to the room temperature. The development of internal stresses influences the microstructure as well as the microscopic mechanical properties [16,17]. Compared with the sintering mismatch stresses which have been studied profoundly over the past decades, little work to date has been done to analyze the distribution and the evolution of residual stresses in the co-fired multilayered systems. A common method for the investigation of residual stresses is Raman spectroscope, which has been utilized for measuring the residual stresses in a number of systems $[18,19]$. The favorable spatial resolution of Raman technique is helpful to explore the relationship between the 
residual stresses evolution and the microstructure of NIPS membranes.

The objective of this study was to investigate the effect of structure on the densification mismatch and the residual stresses of the NIPS membranes. The membranes made of 3 mol\% yttria-stabilized zirconia (YSZ) were sintered from $1200{ }^{\circ} \mathrm{C}$ to $1500{ }^{\circ} \mathrm{C}$, the curvature and microstructure evolution were recorded as a function of temperature. Raman spectroscopy was used to obtain the residual stresses. The analytical model proposed by Cai et al. [10] was employed for a semiquantitative analysis of the densification rate mismatch and the sintering mismatch stresses.

\section{Experimental procedure}

\subsection{Preparation of YSZ NIPS membranes}

The suspension for the preparation of the YSZ NIPS membranes consisted of $50 \mathrm{wt} . \%$ YSZ powders (>99.9\%, 200 nm, Jiangxi Fanmeiya Materials Co., Ltd.), 40 wt.\% Nmethyl-2-pyrrolidone (NMP) (AR Grade, Sinopharm, China) and 10 wt.\% polyethersulfone (PESf) (BD-5, Beishide Chemical Reagent Factory). All the raw materials were high energy ball milled for $24 \mathrm{~h}$ to ensure the well mixing. The ball milled suspension was transferred to a sealed vessel and degassed under vacuum for 1 $\mathrm{h}$. Then the degassed suspension was casted on a flat glass using a film applicator (FA102D, Fuan Enterprise Co., Ltd.), where a micrometer gauged scarper was used to control the thickness. Two kinds of casting thickness were used, $1000 \mu \mathrm{m}$ and $800 \mu \mathrm{m}$. The casted wet membranes were transferred into a water bath for $48 \mathrm{~h}$ immersion to complete the phase separation process. The solidified membranes were dried for $12 \mathrm{~h}$ 
in air to obtain the membrane precursors (membrane as prepared, to distinguish from green membranes without organic binder). The dry thicknesses after the phase inversion process for the two membranes were $\sim 850 \mu \mathrm{m}$ and $680 \mu \mathrm{m}$, respectively.

\subsection{Camber evolution and microstructure characterization}

To observe the curvature evolution of YSZ NIPS membranes, an in-situ observation was conducted, in which a flat plate with a dimension $40 \mathrm{~mm} \times 0.5 \mathrm{~mm}$ was cut from the membrane precursor and placed on an alumina substrate with the FVL on the top side and put into a tube furnace (Carbolite, UK). A thermocouple was placed adjacent to the membrane for temperature recording. The membrane was first heated at $800{ }^{\circ} \mathrm{C}$ for $1 \mathrm{~h}$ to eliminate the organic binder with a heating rate of $5{ }^{\circ} \mathrm{C} / \mathrm{min}$ and subsequently heated to $1500{ }^{\circ} \mathrm{C}$ at the same heating rate. Photographs of the curvature evolution were taken at $25{ }^{\circ} \mathrm{C}$ intervals over the temperature range of interest, on which the curvature was measured by the following steps: three points were placed at the middle line of the membrane to draw a circle with radius $r$, and the curvature $k$ was calculated by the reciprocal of $r$. A positive curvature was denoted when the membrane bended towards the SLL.

The membranes used for microstructure characterization were sintered in a chamber furnace (Carbolite, UK) and immediately cooled down once reach its target temperature to prevent further sintering. The morphologies of fractured cross section were examined using a scanning electron microscope (SEM, JEOL JSM-7800F Prime). The grain size and porosity were measured on the polished and thermal etched (conducted at $100{ }^{\circ} \mathrm{C}$ 
below the sintering temperature for $30 \mathrm{~min}$ ) surfaces by processing the SEM micrographs using the Image $\mathrm{J}$ software. The positions for measurements were located at middle line of the thickness of the FVL and the SLL. To reduce the error in the determination of porosity and grain size by image analysis, at least $600 \mu \mathrm{m}^{2}$ areas and 200 random grains were measured for the statistical analysis.

For accessing the finger-like voids at different strata of the membranes, a fraction of membranes was grinded off from the top or bottom to expose the voids. The total thickness of the membranes was first measured, then the membranes were mounted flat in epoxy resin, and then grinded off $10 \%, 40 \%$ and $70 \%$ of the total thickness by controlling the residual thickness of membranes. SEM images were taken for each grinded membrane, the voids diameters and the voids area fraction were counted using the Image $\mathrm{J}$ software.

\subsection{Residual stress measurement}

The residual stresses were measured by Raman spectroscopy (LabRAM HR Evolution Horiba, France, $532 \mathrm{~nm}$ ) at room temperature. Spectral resolution of the investigated Raman peak range was $\sim 0.65 \mathrm{~cm}^{-1}$. The obtained spectra were deconvoluted for the stress calculation using Gaussian-Lorentzian function (Labspec 6 analysis software, Horiba, France). The laser spot size was about $2 \mu \mathrm{m} .10$ measurements were conducted around the designed positions on the side surface of the membranes to estimate the statistical significance. The stresses were calculated from the Raman peak shift, $\Delta v$, by [20]: 


$$
\sigma=\frac{1-v}{\Pi} \frac{E}{E_{0}} \Delta v
$$

where $E / E_{0}$ is the ratio between the elastic modulus of the probe position and that of the dense YSZ materials which is $200 \mathrm{GPa}$ [18]. The elastic modulus of probe positions was calculated with Ramakrishnan's model [21]. $\Pi$ is the piezo-spectroscopic constant, which is $2.01 \mathrm{~cm}^{-1} / \mathrm{GPa}$ for the peak at $465 \mathrm{~cm}^{-1}$ [18]. The Poisson ratio $v$ is estimated to be 0.3 for all the specimens. All the error bars showed standard deviations in this work.

\section{Results}

\subsection{Porous structures of YSZ NIPS membranes}

\subsubsection{Sponge-like structure and finger-like voids in macroscale}

The membranes with a casting thickness of $1000 \mu \mathrm{m}$ were mainly characterized and discussed, unless otherwise specified, the results were for the membranes with 1000 $\mu \mathrm{m}$ casting thickness. Fig. 1 presented the SEM images of the green membrane (sintered at $800{ }^{\circ} \mathrm{C}$ for $3 \mathrm{~h}$ to remove the organic binder) and the membrane sintered at $1450{ }^{\circ} \mathrm{C}$ without dwelling. The unique multilayered structure of the NIPS membrane consisted mainly of three layers: the skin layer, the FVL and the SLL. The upper skin layer and FVL occupied $\sim 70 \%$ of the thickness with a plurality of finger-like voids (sketched in Fig. 1a) penetrating through the FVL, and the lower SLL. The inserted image in Fig. 1a showed the skin layer (specimen sintered at $1450{ }^{\circ} \mathrm{C}$ ), beneath which the finger-like voids initiated. There were transition regions between the different layers, instead of distinct interface. Moreover, there was a thin wall (highlighted in Fig. 1a) separating 
the finger-like voids which also possessed a sponge-like network structure, the same as that of the SLL (shown in Fig. 1b, d). Then the primary porous structures of the NIPS membranes were composed of two parts: the sponge-like structure and the finger-like voids in macroscale.

Detailed microstructures of the green membrane and the membrane sintered at $1450{ }^{\circ} \mathrm{C}$ were compared in Fig. 1b-g, including three featured positions in the NIPS membranes. These images showed remarkable densification and grain growth of the sponge-like structures after sintering. Images showed that the densification occurred mainly in the struts, and the voids surrounded by structs have not been eliminated during sintering because the void size was much larger than the initial grain size. Besides the spongelike structure, the finger-like voids were also preserved for all the membranes sintered at different temperature, which agreed with the previous study [22].
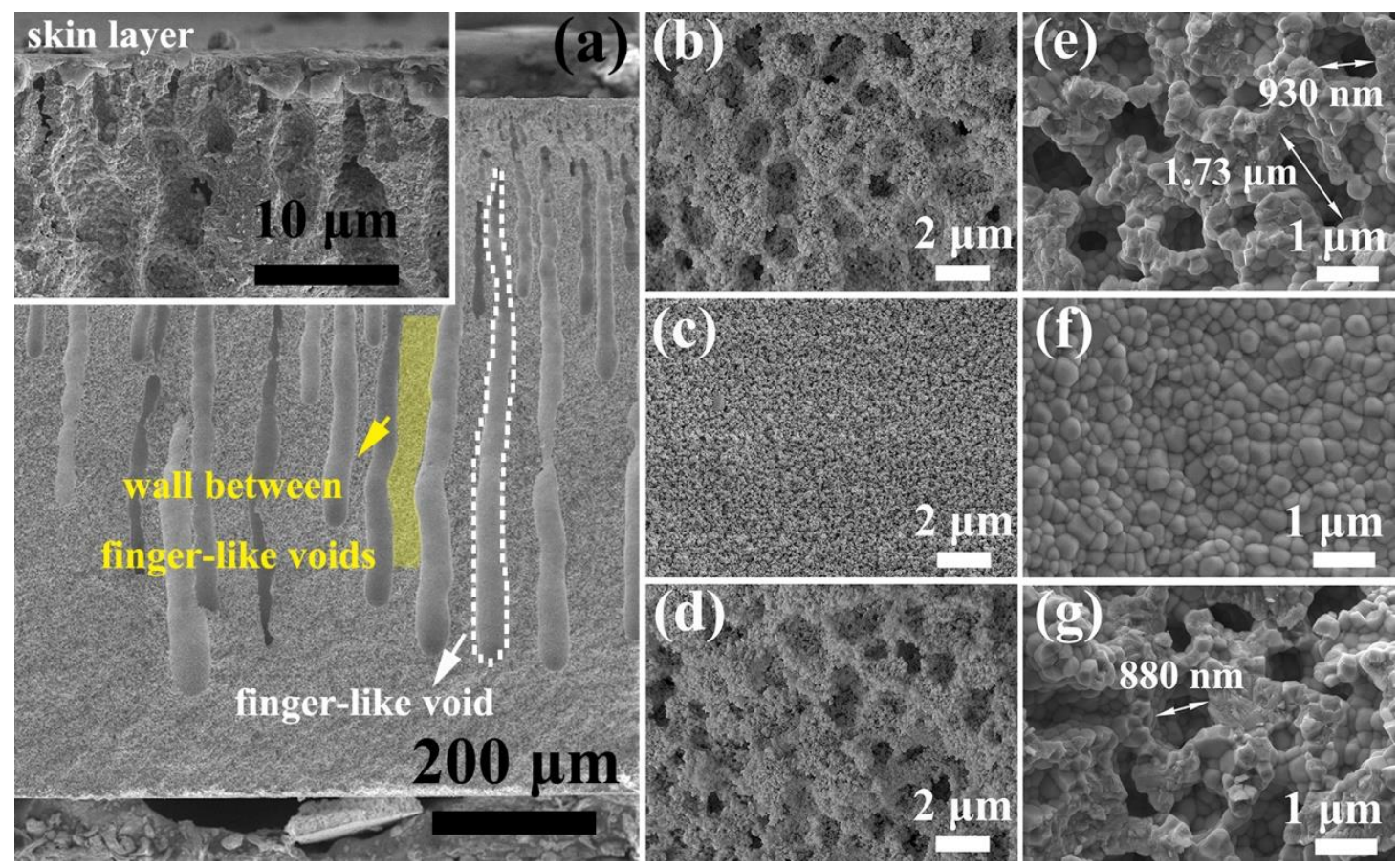

Fig. 1. SEM images of the YSZ NIPS membranes: (a) global cross-sectional of the green membrane, inserted image showed the skin layer of top surface; wall between the 
finger-like voids of (b) green membrane and (e) $1450{ }^{\circ} \mathrm{C}$ sintered membrane; surface of the finger-like voids of (c) green membrane and (f) $1450{ }^{\circ} \mathrm{C}$ sintered membrane; SLL of (d) green membrane and (g) $1450{ }^{\circ} \mathrm{C}$ sintered membrane.

\subsubsection{Hierarchical structure of finger-like voids}

Fig. 2 showed the outlines of the finger-like voids on different directions. Images from the side of the membranes (Fig. 2a) showed that these voids initiated beneath the skin layer and grew larger in size horizontally as they propagate across the cross-section. The section views at three different strata of the membrane (Fig. 2b-d) further demonstrated that the finger-like voids were conic shape and the number of voids decreased along the thickness as well. The initialization and hierarchical structure of the finger-like voids could be interpreted by the Rayleigh-Taylor Instability theory [23]. The periodic perturbations on the interface between the suspension and the coagulant (water) was facilitated by a difference in density, and the interface moved towards to the suspension side because of the extraction of solvent (NMP) and contraction of polymer (PESf). 


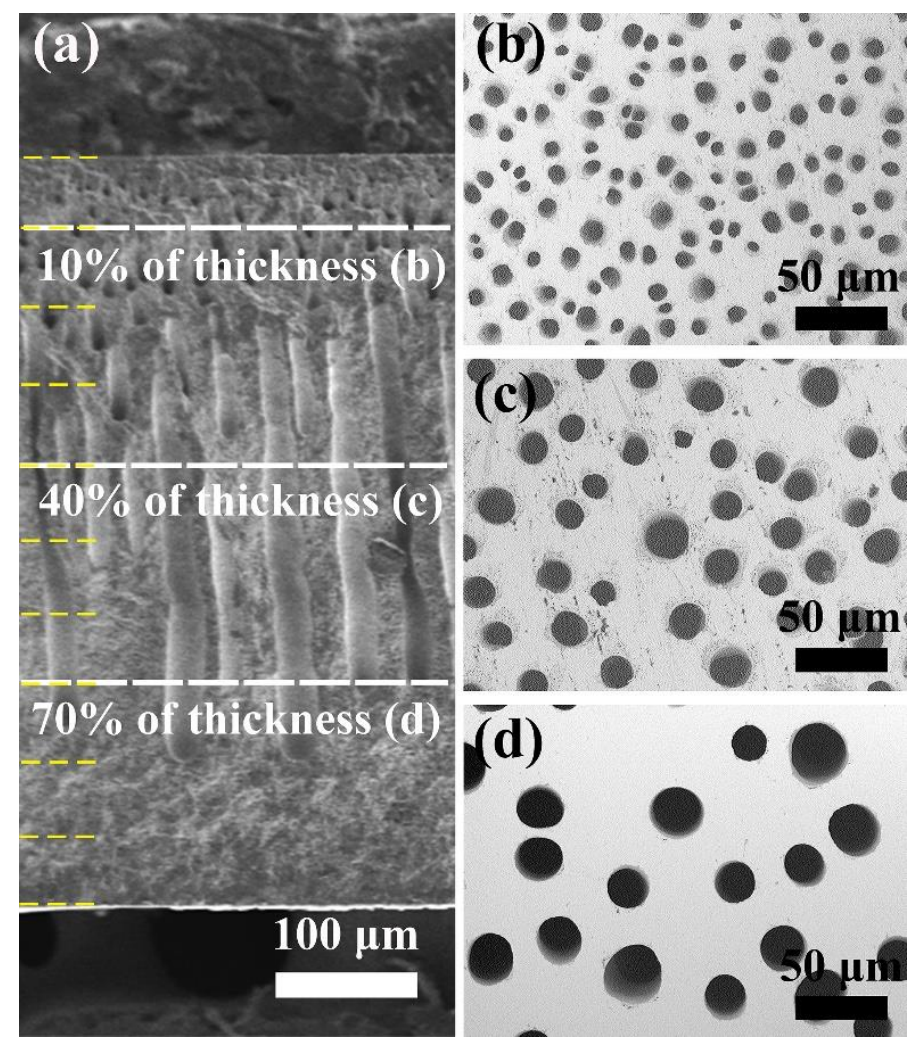

Fig. 2. (a) SEM image from the side of YSZ NIPS membrane sintered at $1450{ }^{\circ} \mathrm{C}$ with the labelled positions; (b)-(d) section views of finger-like voids at $10 \%, 40 \%$ and $70 \%$ of the thickness. The casting thickness of the membrane was $1000 \mu \mathrm{m}$.

\subsection{Densification of YSZ NIPS membranes}

\subsubsection{Densification of sponge-like structures}

The porosity and grain size of the SLL and the wall between the finger-like voids under different sintering temperature were shown in Fig. 3, both regions displayed a spongelike structure. The grain size of all the specimens monotonically increased from $\sim 100$ $\mathrm{nm}$ at $1200{ }^{\circ} \mathrm{C}$ to $\sim 300 \mathrm{~nm}$ at $1500{ }^{\circ} \mathrm{C}$, and no significant difference in the grain size was identified between these two regions. In the investigated temperature range, the porosity of wall between the finger-like voids was higher than that of the SLL throughout the sintering process. The inserted SEM images showed the polished and 
thermal etched SLL sintered at $1250{ }^{\circ} \mathrm{C}$ and $1400{ }^{\circ} \mathrm{C}$, no preferred orientations of the pores and grains in the sponge-like structure were observed.

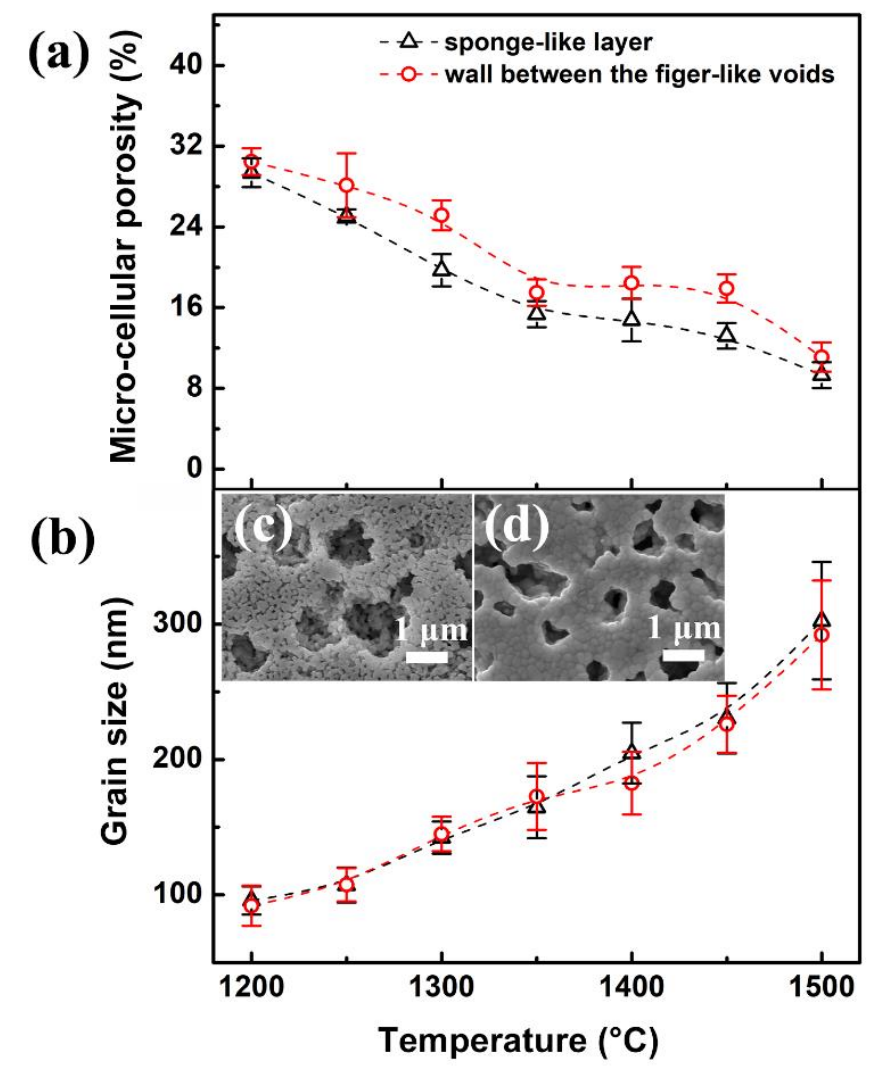

Fig. 3. Variations of (a) porosity and (b) grain size of the wall between the finger-like voids and the SLL in YSZ NIPS membranes; inserted SEM images showed polished and thermal etched SLL of membranes sintered at (c) $1250{ }^{\circ} \mathrm{C}$ and (d) $1400{ }^{\circ} \mathrm{C}$.

\subsubsection{Densification of finger-like voids}

Fig. 4 presented the variation of voids area fraction and voids diameter of the fingerlike voids at three different strata of the membranes. The measurement positions were corresponding to the schematics in Fig. 2, which were located at $10 \%, 40 \%$ and $70 \%$ of the thickness of the membranes. According to this profile, the voids diameters decreased with increasing temperature, and increased with the penetration depth 
towards the SLL. The voids area fraction fluctuated around $20 \%$ as a function of the depth and the temperature. It should be noted that the results were obtained based on the section views in Fig. $2 b-d$, and only the finger-like voids were taken into consideration while the porosity of sponge-like structures surrounded were ignored. The voids area fraction was not significantly affected by the decreasing of voids diameter because the shrinkage of finger-like voids was proportional to that of the surrounded matrix. This result was consistent with the characterization of $\mathrm{Al}_{2} \mathrm{O}_{3} \mathrm{NIPS}$ membrane by synchrotron-radiation computed tomography which demonstrated that the volume fraction of finger-like voids went through a rapid increase beneath the skin layer and varied slightly throughout the subsequent section until reaching the SLL [24]. The depending of densification mismatch within the NIPS membranes on the shrinkage of porous structures will be discussed later. 


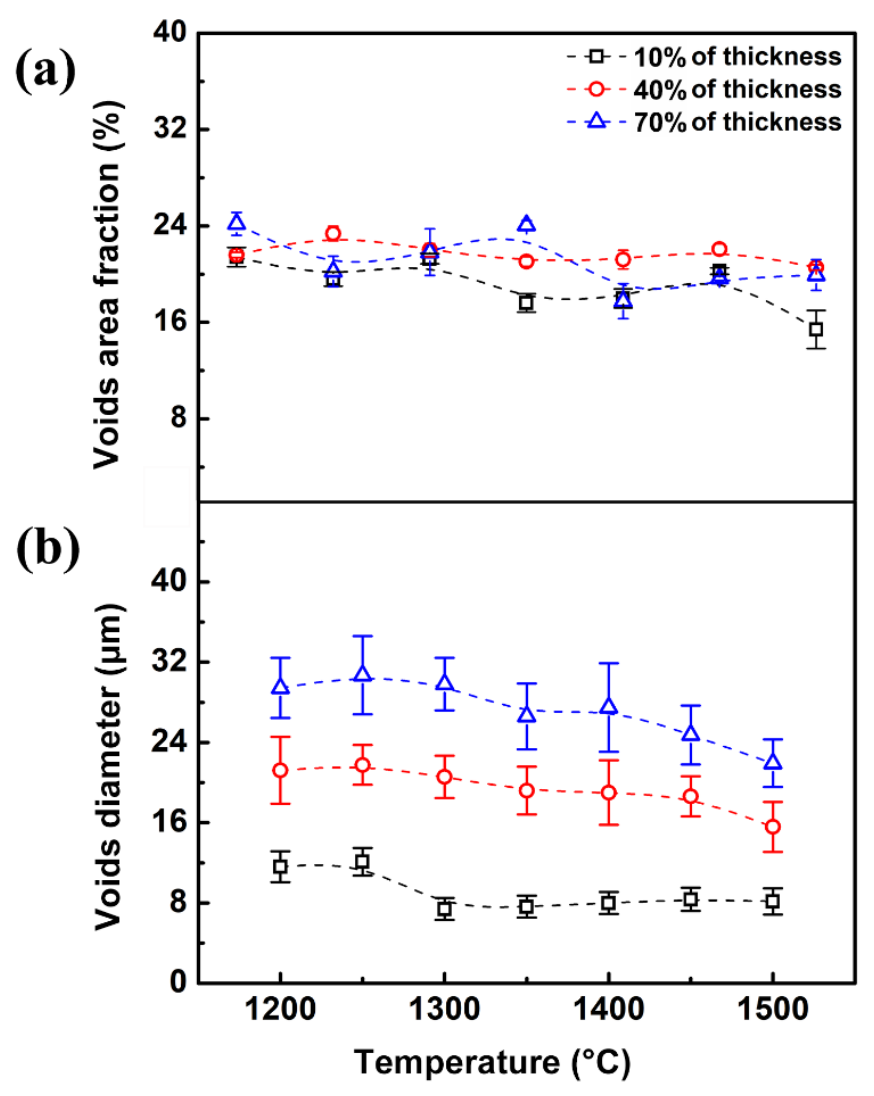

Fig. 4. Variations of (a) voids area fraction and (b) voids diameter of the finger-like voids at different strata of the YSZ NIPS membranes.

\subsection{Camber evolution during sintering}

Fig. 5 represented the camber evolution of the YSZ NIPS membrane with the increasing temperature. The membrane started bending towards the SLL at about $1225^{\circ} \mathrm{C}$, indicating that the SLL shrank more than the FVL at this temperature. The camber reached the maximum at $1300^{\circ} \mathrm{C}$, and then gradually decreased to flat shape at $1400^{\circ} \mathrm{C}$, as shown in Fig. 5c-e. After this, the membrane bended towards the opposite direction (Fig. 5f), and the camber slightly increased with the increasing temperature up to $1450{ }^{\circ} \mathrm{C}$ (Fig. $5 \mathrm{~g}$ ). Then the arched membrane recovered the flat shape again at $1463{ }^{\circ} \mathrm{C}$, as shown in Fig. $5 \mathrm{~h}$. 

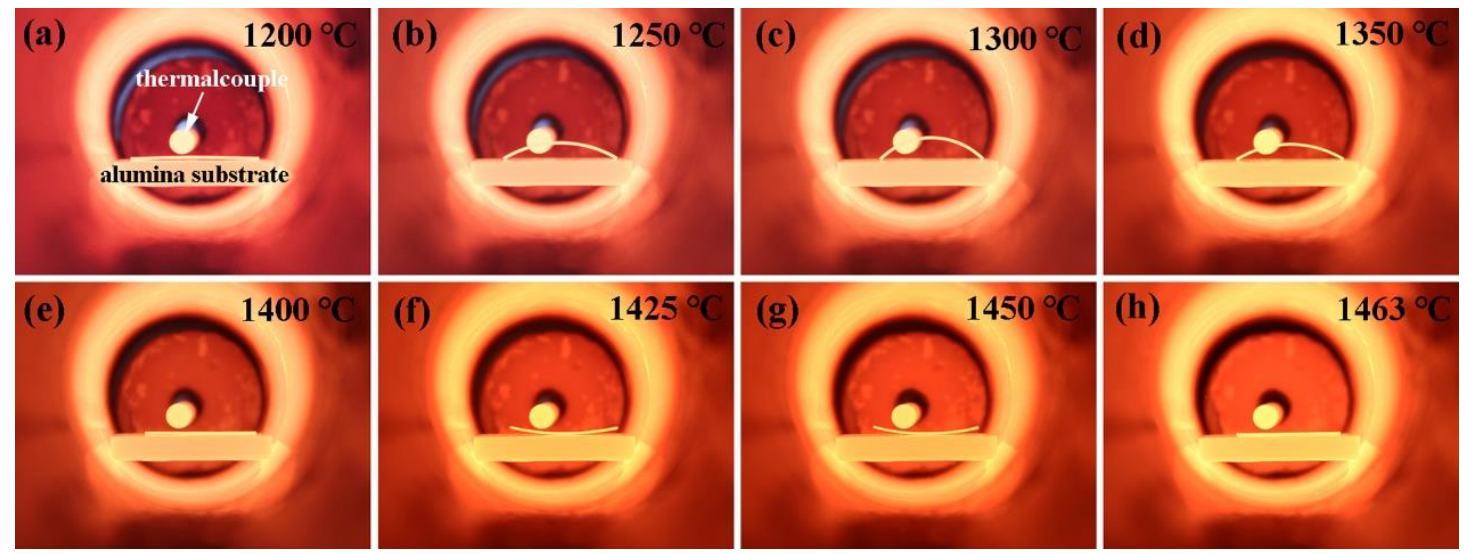

Fig. 5. Series of photographs showing the in-situ observed camber evolution of the YSZ NIPS membrane, the FVL was on the top.

Fig. 6 plotted the evolution of camber curvature as a function of temperature (based on

Fig. 5). The curvature development can be divided into three stages by the camber direction: stage I $\left(1200{ }^{\circ} \mathrm{C}\right.$ to $\left.1400{ }^{\circ} \mathrm{C}\right)$, stage II $\left(1400{ }^{\circ} \mathrm{C}\right.$ to $\left.1460{ }^{\circ} \mathrm{C}\right)$ and stage III $\left(1460{ }^{\circ} \mathrm{C}\right.$ to $\left.1463{ }^{\circ} \mathrm{C}\right)$. By adjusting the casting thickness $(800 \mu \mathrm{m})$, YSZ NIPS membranes with small percentage of the SLL ( 10\%) were prepared. The camber evolution was recorded in Fig. 7. The membrane firstly bended towards the opposite direction when compared with the results in Fig. 5. This phenomenon substantiated that a three-layer structure could be appropriate for the elaboration of densification mismatch within the NIPS membranes, however, for the typical structure with a fair proportion of the SLL, the effect of skin layer could not be reflected on the macrodeformation. 


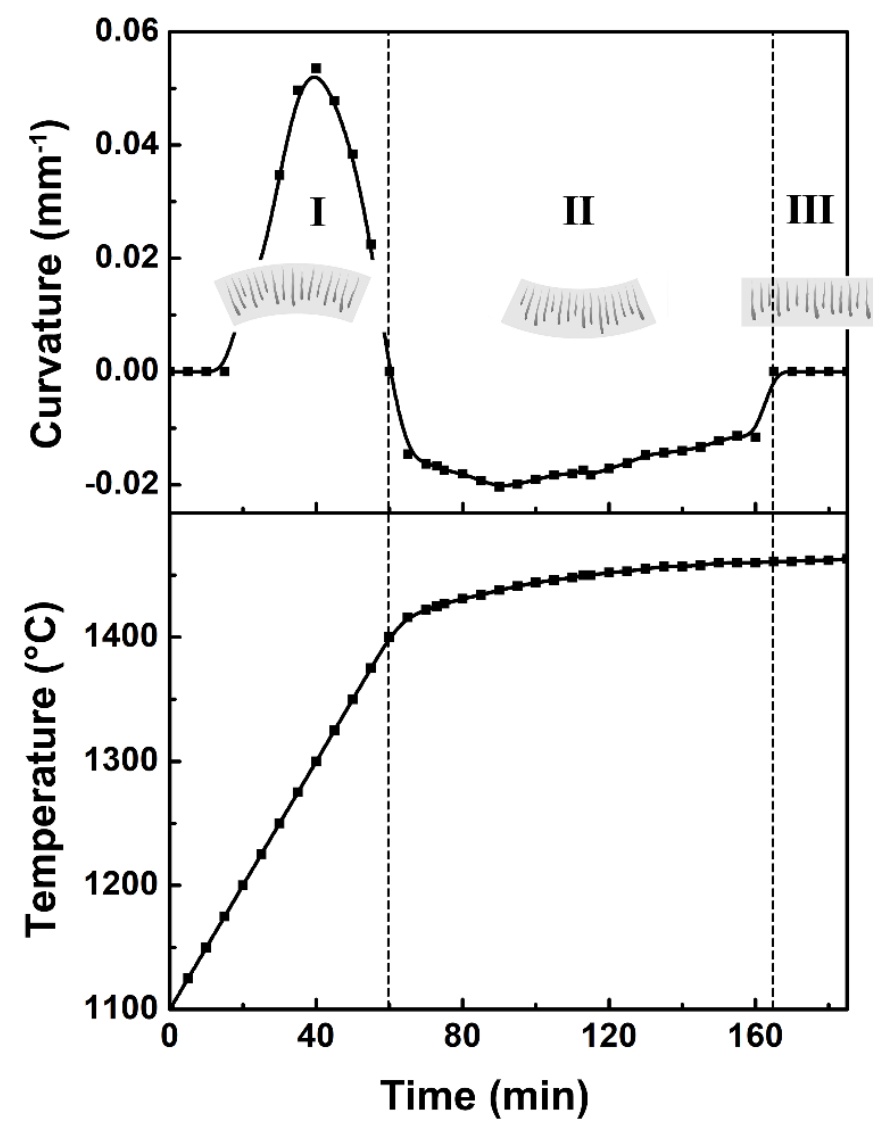

Fig. 6. Curvature development of the in-situ observed camber with temperature and time (shown in Fig. 5). The curvature development was divided into three stages: stage I $\left(1100{ }^{\circ} \mathrm{C}\right.$ to $\left.1400{ }^{\circ} \mathrm{C}\right)$, stage II $\left(1400{ }^{\circ} \mathrm{C}\right.$ to $\left.1460{ }^{\circ} \mathrm{C}\right)$ and stage III $\left(1460{ }^{\circ} \mathrm{C}\right.$ to $1463{ }^{\circ} \mathrm{C}$ ), corresponding to different geometries of the membrane.
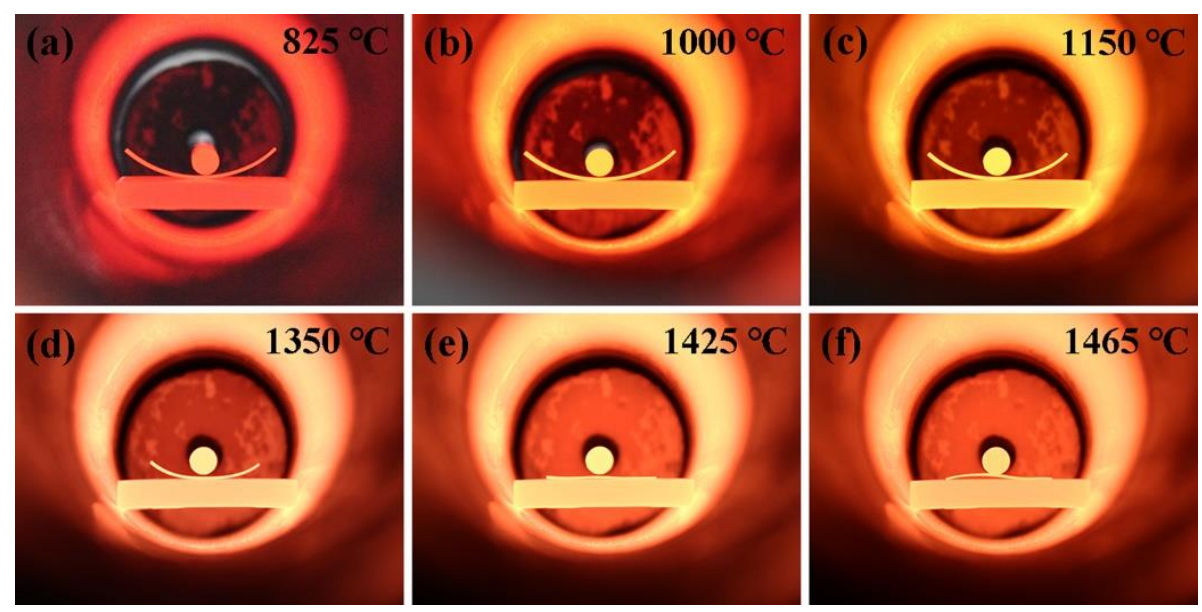

Fig. 7. Series of photographs showing the in-situ observed camber evolution of the YSZ 
NIPS membrane with small percentage of the SLL $(\sim 10 \%)$. The casting thickness of membranes was $800 \mu \mathrm{m}$.

\subsection{Residual stress of YSZ NIPS membranes}

Fig. 8a showed the development of residual stress of the YSZ NIPS membranes with temperature. The measurements were conducted on the side surface of the sintered membrane, and for comparison purposes, the "transition region of SLL" was located at $80 \%$ of the thickness for all the specimens. The states of residual stresses were tensile for all the characteristic positions before $1400^{\circ} \mathrm{C}$, this temperature was corresponding to the inflection point of curvature direction, also the inflection point of the sinusoidal variation of residual stresses for all three probe positions. After that, the residual stresses of the transition region of SLL turned into compressive. At the beginning $\left(1200{ }^{\circ} \mathrm{C}\right)$ and the end $\left(1500{ }^{\circ} \mathrm{C}\right)$ of the process, the residual stresses at probe positions were near zero. Fig. $8 \mathrm{~b}$ represented the variation of biaxial sintering mismatch stresses across the thickness in the bilayer structure [10]. The vertical axis corresponds to the thickness of the bilayer system and the horizontal axis corresponds to the sintering mismatch stress. According to the profile, the interface of the layer sintered faster (point A) and top surface of the layer sintered slower (point B) are the positions of the maximum tensile stress in each layer. The sintering mismatch stress depends on whether the free shrinkage strain is larger than the constrained shrinkage strain. For the layer sintered faster, the shrinkage strain is reduced by the layer sintered slower, thus, the sintering mismatch stresses of the layer sintered faster are tensile. The constraint is most 
severe at the interface (point A), and the sintering mismatch stress here is the largest. However, the theoretical model was used for the transient viscoelastic stress caused by densification mismatch, the relevancy between the viscoelastic stress and residual stress was still remain discussion.

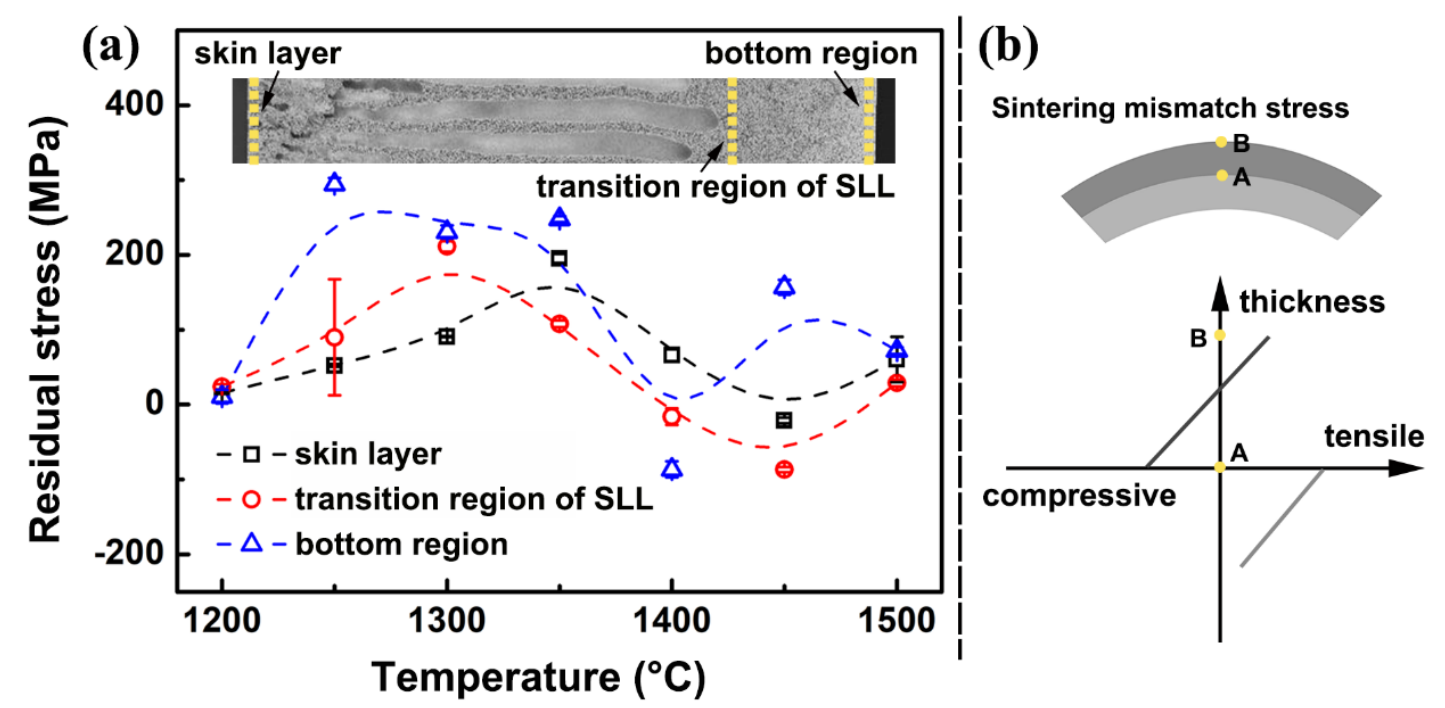

Fig. 8. Residual stress and sintering mismatch stress profiles: (a) variation of residual stresses at characteristic positions of YSZ NIPS membranes; (b) schematic diagram of the sintering mismatch stresses in bilayer membrane, in which points A and B showed the positions of the maximum tensile stress in each layer.

\section{Discussion}

\subsection{Densification mismatch of YSZ NIPS membranes}

The distortion confirmed the presence of densification mismatch during the sintering of YSZ NIPS membranes. The temperature difference between the air and the alumina plate might occur due to the differences in thermal conductivity and heat capacity, however, this temperature difference would play a minor role on the temperature profile 
of the YSZ NIPS membrane because the heat conduction and thermal radiation dominated in the heating process $[25,26]$. Therefore, it is reasonable to assume the temperature as uniform. As a homogeneous material membrane, the green density variation was the only reason for densification mismatch. The porous structures of YSZ NIPS membranes were classified into two morphologies: the sponge-like structure and the finger-like voids in macroscale. The sintering potential of pores is related to the differential chemical potential for diffusing species which is inversely proportional to the curvature of pore surface $[27,28]$. Then the finger-like voids were expected to less contribute to the sintering driving force due to their low surface curvature. As shown in Fig. 2, the finger-like voids were uniformly distributed in the sponge-like structure matrix, thus these voids should shrink at the same rate as the matrix, and the voids size during sintering can be predicted from [27,29]:

$$
D=D_{0}\left(\frac{\rho_{m 0}}{\rho_{m}}\right)^{1 / 3}
$$

where $D$ is the finger-like voids diameter during sintering, $D_{0}$ is the initial voids diameter, $\rho_{m 0}$ and $\rho_{m}$ are the initial density and the density during sintering of the matrix respectively. Fig. 9 represented the finger-like voids size at $40 \%$ of thickness which was predicted by Eq. (2), there was a good agreement between the experimental and the theoretically obtained voids diameter. The results were also in agreement with the variation of voids area fraction (Fig. 4a), which remained almost constant because the shrinkage of finger-like voids was proportional to that of the matrix. 


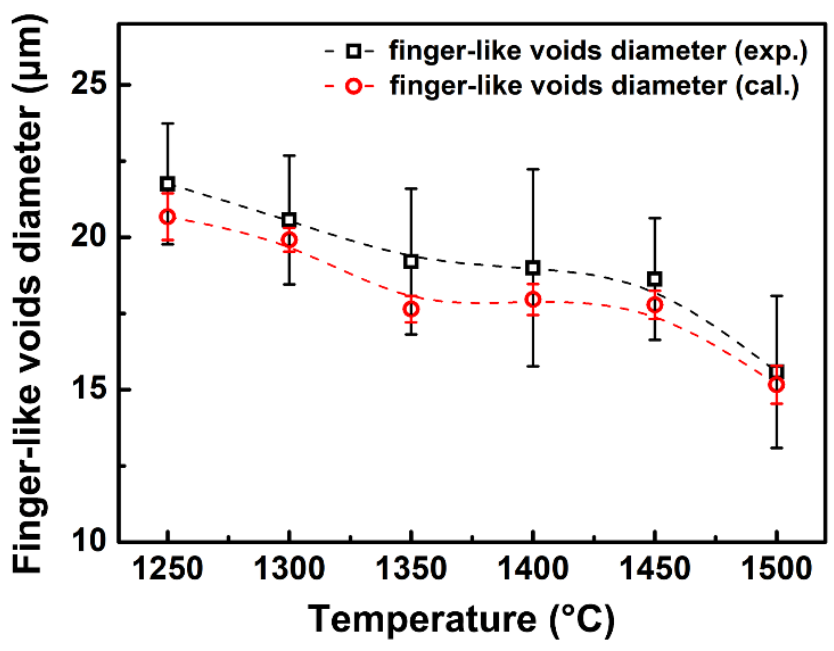

Fig. 9. Comparison between theoretical calculated and experimental obtained fingerlike voids diameter at $40 \%$ of the membrane thickness.

The sponge-like structure matrix determined the shrinkage rate then since the sintering potential of intergranular porosity was much larger than that of the finger-like voids. Because the phase separation by liquid-liquid demixing is gradually extended from the top surface to the bottom surface, the simultaneous solvent evaporation and moisture (non-solvent) condensation can cause a viscosity increasing towards the bottom surface $[22,30-32]$. Then the sponge-like structures exhibit variation over the membrane thickness. The porosity of sponge-like structure gradually increased along the thickness, as shown in Fig. 3a. The matrix with higher density had a faster densification strain rate initially, following by a curvature increase towards the SLL (stage I in Fig. 6). As the sintering process continued, both SLL and FVL gradually densified, but their densification rate decreased due to the decreasing sintering driving force induced by grain growth [33]. Whilst, the high porosity of the wall between the finger-like voids allowed a further densification of the FVL. A continued shrinkage of the upper layer 
made the camber to bend towards the FVL (stage II in Fig. 6). The increasing density resulted in an increase in viscosity as well, forming a higher resistance for distortion, which can be regarded as a reason for the smaller curvature in stage II. Furthermore, the gravity acted against the distortion throughout the whole sintering process, contributing to the final flat shape of membrane (stage III in Fig. 6) [34,35].

The densification mismatch between the skin layer and the FVL became dominate when the proportion of SLL was small. The camber behavior of NIPS membrane mainly consisted of these two layers (the skin layer and the FVL, Fig. 7) had reflected the green density variation between these two layers. The void size of the finger-like voids beneath the skin layer was comparable to that of the sponge-like structure or even denser, which suggested that the finger-like voids at this region could be involved in sintering. In this case, the densification mismatch between the skin layer and FVL could be reflected on the macro-deformation as shown in Fig. 7. The shrinkage in finger-like voids diameter at $10 \%$ of the thickness stopped at $1300{ }^{\circ} \mathrm{C}$ (Fig. $4 \mathrm{a}$ ) whilst the other two positions kept changing, which also suggested a tight packing of YSZ particles near the skin layer. The favorable particle coordination facilitated the elimination of intergranular porosity and consequently decreased the driving force for shrinkage. The temperature at which the voids diameter stopped changing $\left(1300{ }^{\circ} \mathrm{C}\right)$ was lower than that of the change in curvature direction $\left(1400^{\circ} \mathrm{C}\right)$, suggesting that the termination of shrinkage in voids diameter should be attribute to the complement of sintering process rather than the sintering mismatch stress.

The individual sintering behaviors of different layers of NIPS membrane were difficult 
to analyze because the interface between layers were indistinct and the structure exhibited gradients. Then it is necessary to simplify the geometry of the specimens for the calculation of densification mismatch. The tri-layered membranes were reduced to two layers, the FVL and the SLL, and the variation of sponge-like structure matrix within each layer were ignored. The normalized curvature rate of the cambered membrane is related to the densification rate mismatch between layers by $[7,10]$ :

$$
\Delta \dot{\varepsilon}=\left[\frac{6(m+1)^{2} m n}{m^{4} n^{2}+2 m n\left(2 m^{2}+3 m+2\right)+1}\right]^{-1} \dot{k}
$$

where $\Delta \dot{\varepsilon}$ is the densification strain rate mismatch, $\dot{k}$ is the normalized curvature change rate, $m$ and $n$ are the thickness ratio and viscosity ratio of the two adjacent structures respectively, given by $m=\frac{h_{s}}{h_{f}}$ and $n=\frac{\eta_{s}}{\eta_{f}}$, and the subscript $s$ and $f$ represent the SLL and the FVL respectively. The $\dot{k}$ was calculated with the data presented in Fig. 6 , and $m$ was taken as 0.3 for all the membranes. Moreover, the densification rate mismatch is dependent on the viscosity ratio $n$ and it can be figured out with several calculations. The uniaxial viscosity in Eq. (2) can be related to the shear viscosity $G$ and the viscous Poisson's ratio $v$ by [36]:

$$
\eta=2 G(1+v)
$$

where the Poisson's ratio $v$ is calculated with [16]:

$$
v=\frac{1}{2} \sqrt{\frac{\rho}{3-2 \rho}}
$$

and the normalized shear viscosity $G$ is defined as [37]:

$$
G=\rho^{2} G_{0}
$$

where $\rho$ is the relative density of the compact, and $G_{0}$ is the shear viscosity of a fully dense material. For the simplified bilayer NIPS membranes with the same layer 
materials and similar pore structures but different initial layer porosity, the $G_{0}$ is the same $[35,38]$. Then with Eqs. (4)-(6), the viscosity ratio between the SLL and the FVL can be written as:

$$
n=\frac{\rho_{s}^{2}}{\rho_{f}^{2}} \sqrt{\frac{\rho_{s}}{3-2 \rho_{s}} \frac{3-2 \rho_{f}}{\rho_{f}}}
$$

Fig. 10 presented the calculated densification strain rate mismatch within the NIPS membranes as a function of the sintering temperature, where the positive part before $1300{ }^{\circ} \mathrm{C}$ represented that the strain rate of the SLL was higher than that of the FVL, and the negative part was on the opposite. The inserted image showed the normalized curvature rate, in which the variation of curving rate was in sync with the densification strain rate mismatch. The result was limited to the temperatures where the curvature could be effectively measured. As demonstrated in Eq. (2), the curving rate is zero when the densification strain rates of the constituent layers are converging, which is corresponding to the maximum curvature of the cambered membranes. This correlation between the curvature and the densification strain rate mismatch was proved by the maximum curvature at $1300{ }^{\circ} \mathrm{C}$ and that at the $1450{ }^{\circ} \mathrm{C}$.

As discussed above, the green density variations of the sponge-like structure were the reasons for the densification mismatch of the NIPS membranes during sintering, and the unsynchronized decrease of densification rate with the increasing porosity were responsible for the reversal of camber direction. The densification strain rate mismatch calculated by the simple theoretical model was in agreement with the experimental results, however, the theoretical analyses here only provided a semiquantitative analysis about the sintering of NIPS membranes, under the precondition of ignoring the porosity 
gradient of the sponge-like structure matrix within each layer.

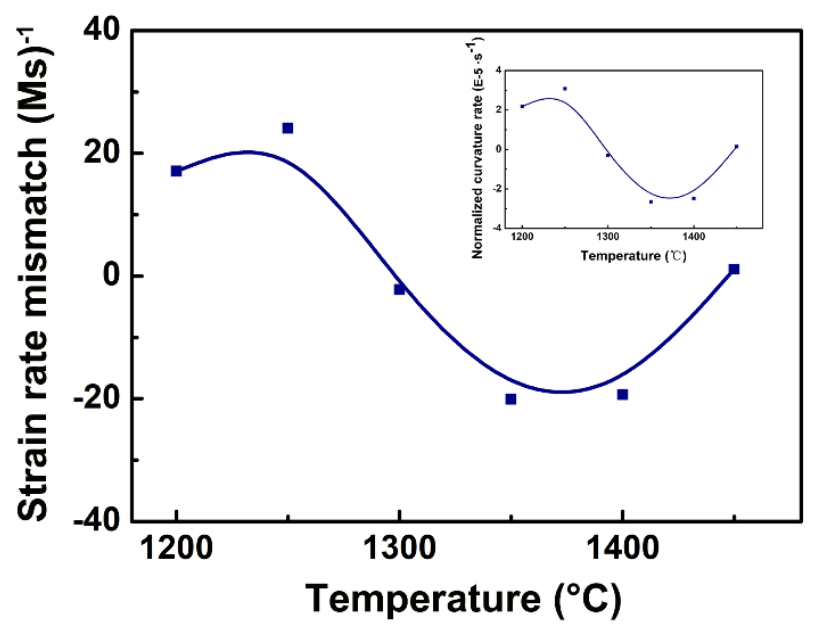

Fig. 10. Theoretically calculated densification strain rate mismatch versus sintering temperature, and the inserted image showed experimental normalized curving rate with temperature.

\subsection{Residual stresses of YSZ NIPS membranes}

The sintering mismatch stresses can be developed due to the difference in the densification. Although the camber caused by densification mismatch lead to partial relaxation of the sintering mismatch stresses, the residual stresses could still exist in membranes, and the residual stresses basically are proportional to the sintering mismatch stresses [8]. In this study, the densification mismatch was believed to be the only origin of residual stresses because there was no thermal expansion coefficient mismatch in the YSZ NIPS membranes [39].

For sintering mismatch stresses in conventional bilayer system (Fig. 8b), the maximum tensile stress of the layer that sintered faster occurs at the interface. Before $1400{ }^{\circ} \mathrm{C}$ (stage I in Fig. 6), the SLL shrank more, indicating a tensile stress within this layer and 
a larger stress at the transition region. However, creep is capable of releasing the sintering mismatch stress, and the effective creep rate is expected to increase with the increasing porosity [40], which can explain that the residual stress at the bottom region was larger than that of the transition region of SLL. Different from theoretical model, the densification mismatch occurred between the FVL and the skin layer could generate the sintering mismatch stresses as well. The skin layer shrank more than the FVL until $1425{ }^{\circ} \mathrm{C}$ as evidenced in Fig. 7, however, with the addition of SLL, the direction of curvature changed to the opposite, which was supposed to leave the skin layer in tensile stress. After $1400{ }^{\circ} \mathrm{C}$ (stage II in Fig. 6), the transition region of SLL turned into compressive stress because of the smaller shrinkage during this stage. The sintering mismatch stresses at the transition region of SLL during stage I can be given by [10]:

$$
\sigma_{s}=\frac{m^{2} n(4 m+3)+1}{m^{4} n^{2}+2 m n\left(2 m^{2}+3 m+2\right)+1} \eta_{s} \Delta \dot{\varepsilon}
$$

The parameters are defined in Eq. (3). As demonstrated in Eq. (8), the largest sintering mismatch stresses develop when the product of the densification rate mismatch and the viscosity is maximum. The correlation between the residual stresses and the sintering mismatch stresses suggested a similar variation of them. The evolution of the residual stresses at the transition region of SLL in Fig. 8 obeyed an approximate sinusoidal pattern to that of the densification strain rate mismatch (as shown in Fig. 10), but different phase, which was expected to be caused by the variation of viscosity. The absence of residual stress at $1200{ }^{\circ} \mathrm{C}$ and $1500{ }^{\circ} \mathrm{C}$ were attributed to the incipient densification mismatch and the relaxation of stress by creep under the gravity respectively. 
The measurement of residual stresses involves an error source. The elastic moduli of all the specimens were calculated by the theoretical model which might overestimate the value. Nevertheless, the residual stress states measured with Raman spectroscopy were in good agreement with the theoretical model.

\section{Conclusions}

In this study, the tri-layered YSZ membranes were fabricated using a combined NIPS and sintering method. The membranes were composed of the skin layer, the FVL and the SLL. It was found that the density variations of the sponge-like structure were the main reason for the densification mismatch, and the unsynchronized decrease of densification strain rate with the increasing porosity were responsible for the reversal of camber direction. The finger-like voids could be treated as macro-features embedded in the sponge-like structure matrix which made no contribution to the sintering potential. Raman spectrum demonstrated the state and the distribution of residual stresses at the characteristic locations of the YSZ NIPS membranes. The residual stresses states were in agreement with the sintering mismatch stresses predicted by a theoretical model. The variation of residual stresses obeyed an approximate sinusoidal pattern, which was believed to have a correlation with the strain rate mismatch. Further, the densification strain rate mismatch within the NIPS membranes was quantified with an in-situ monitored curving rate evolution combined with the porosity variation observation. These results can be used to improve the performance of NIPS membranes. 


\section{Acknowledgement}

This work was supported by the National Natural Science Foundation of China (Grant No. 51402058), the research fund of Shanghai Committee of Science and Technology (Grant No. 14ZR1422900), and CNPEC (China Nuclear Power Engineering Co.,Ltd.) financial support (Grant No. 007-EC-B-2014-C83-PS10-00065).

\section{Reference}

[1]X. Tan, S. Liu, K. Li, Preparation and characterization of inorganic hollow fiber membranes, J. Memb. Sci. 188 (2001) 87-95. doi:10.1016/S0376-7388(01)00369-6. [2]T. Li, Z. Wu, K. Li, A dual-structured anode/Ni-mesh current collector hollow fibre for micro-tubular solid oxide fuel cells (SOFCs), J. Power Sources. 251 (2014) 145-151. doi:10.1016/j.jpowsour.2013.11.043.

[3]F. Guo, G. Wang, Z. Jiang, Y. Liu, X. Zhao, P. Xiao, Growth of carbon nanofibers/tubes by an in-situ polymerization route without metal-catalyst, Carbon $\mathrm{N}$. Y. 100 (2016) 417-427. doi:10.1016/j.carbon.2016.01.041.

[4]M. Lee, B. Wang, K. Li, New designs of ceramic hollow fibres toward broadened applications, J. Memb. Sci. 503 (2016) 48-58. doi:10.1016/j.memsci.2015.12.047. [5]L. Liu, X. Tan, S. Liu, Yttria stabilized zirconia hollow fiber membranes, J. Am. Ceram. Soc. 89 (2006) 1156-1159. doi:10.1111/j.1551-2916.2005.00901.x. [6]F.F. Lange, M. Metcalf, Processing-Related Fracture Origins: II, Agglomerate Motion and Cracklike Internal Surfaces Caused by Differential Sintering, J. Am. 
Ceram. Soc. 66 (1983) 398-406. doi:10.1111/j.1151-2916.1983.tb10069.x.

[7]D. Ravi, D.J. Green, Sintering stresses and distortion produced by density differences in bi-layer structures, J. Eur. Ceram. Soc. 26 (2006) 17-25. doi:10.1016/j.jeurceramsoc.2004.10.032.

[8]A.G. Evans, Considerations of Inhomogeneity Effects in Sintering, J. Am. Ceram. Soc. 65 (1982) 497-501. doi:10.1111/j.1151-2916.1982.tb10340.x.

[9]P.Z. Cai, D.J. Green, G.L. Messing, Constrained Densification of Alumina/Zirconia Hybrid Laminates, I: Experimental observations of processing defects, J. Am. Ceram. Soc. 80 (1997) 1940-1948. doi:10.1111/j.11512916.1997.tb03075.x.

[10]P.Z. Cai, D.J. Green, G.L. Messing, Constrained Densification of Alumina/Zirconia Hybrid Laminates, II: Viscoelastic Stress Computation, J. Am. Ceram. Soc. 80 (1997) 1940-1948. doi:10.1111/j.1151-2916.1997.tb03075.x. [11]E. Olevsky, T.T. Molla, H.L. Frandsen, R. Bjørk, V. Esposito, D.W. Ni, A. Ilyina, N. Pryds, Sintering of multilayered porous structures: Part I-constitutive models, J. Am. Ceram. Soc. 96 (2013) 2657-2665. doi:10.1111/jace.12375. [12]D.W. Ni, V. Esposito, C.G. Schmidt, T.T. Molla, K.B. Andersen, A. Kaiser, S. Ramousse, N. Pryds, Camber Evolution and Stress Development of Porous Ceramic Bilayers During Co-Firing, J. Am. Ceram. Soc. 96 (2013) 972-978. doi:10.1111/jace.12113.

[13]D.W. Ni, E. Olevsky, V. Esposito, T.T. Molla, S.P. V Foghmoes, R. Bjørk, H.L. Frandsen, E. Aleksandrova, N. Pryds, Sintering of multilayered porous structures: 
Part II-experiments and model applications, J. Am. Ceram. Soc. 96 (2013) 26662673. doi:10.1111/jace.12374.

[14]D.J. Green, O. Guillon, J. Rödel, Constrained sintering: A delicate balance of scales, J. Eur. Ceram. Soc. 28 (2008) 1451-1466.

doi:10.1016/j.jeurceramsoc.2007.12.012.

[15]A. Ayrikyan, O. Prach, N.H. Khansur, S. Keller, S. Yasui, M. Itoh, O. Sakata, K.

Durst, K.G. Webber, Investigation of residual stress in lead-free BNT-based

ceramic/ceramic composites, Acta Mater. 148 (2018) 432-441.

doi:10.1016/j.actamat.2018.02.014.

[16]R.K. Bordia, R. Raj, Sintering Behavior of Ceramic Films Constrained by a Rigid

Substrate, J. Am. Ceram. Soc. 68 (1985) 287-292. doi:10.1111/j.1151-

2916.1985.tb15227.x.

[17]X. Wang, Z. Chen, A. Atkinson, Crack formation in ceramic films used in solid oxide fuel cells, J. Eur. Ceram. Soc. 33 (2013) 2539-2547.

doi:10.1016/j.jeurceramsoc.2013.04.032.

[18]L. Yang, F. Yang, Y. Long, Y. Zhao, X. Xiong, X. Zhao, P. Xiao, Evolution of residual stress in air plasma sprayed yttria stabilised zirconia thermal barrier coatings after isothermal treatment, Surf. Coatings Technol. 251 (2014) 98-105. doi:10.1016/j.surfcoat.2014.04.009.

[19]I. DeWolf, Micro-Raman spectroscopy to study local mechanical stress in silicon integrated circuits, Semicond. Sci. Technol. 11 (1999) 139-154. doi:10.1088/02681242/11/2/001. 
[20]A.M. Limarga, D.R. Clarke, Piezo-spectroscopic coefficients of tetragonal-prime yttria-stabilized zirconia, J. Am. Ceram. Soc. 90 (2007) 1272-1275. doi:10.1111/j.1551-2916.2007.01622.x.

[21] V.S. Ramakrishnan, N.; Arunachalam, Effective elastic moduli of porous solids, J. Mater. Sci. 25 (1990) 3930-3937. doi:10.1007/BF00582462.

[22]B.F.K. Kingsbury, K. Li, A morphological study of ceramic hollow fibre membranes, J. Memb. Sci. 328 (2009) 134-140. doi:10.1016/j.memsci.2008.11.050. [23]M. Lee, B. Wang, Z. Wu, K. Li, Formation of micro-channels in ceramic membranes - Spatial structure, simulation, and potential use in water treatment, J. Memb. Sci. 483 (2015) 1-14. doi:10.1016/j.memsci.2015.02.023. [24]H. Fang, C. Ren, Y. Liu, D. Lu, L. Winnubst, C. Chen, Phase-inversion tape casting and synchrotron-radiation computed tomography analysis of porous alumina, J. Eur. Ceram. Soc. 33 (2013) 2049-2051. doi:10.1016/j.jeurceramsoc.2013.02.032. [25]D. Salamon, R. Kalousek, J. Zlámal, K. Maca, Role of conduction and convection heat transfer during rapid crack-free sintering of bulk ceramic with low thermal conductivity, J. Eur. Ceram. Soc. 36 (2016) 2955-2959. doi:10.1016/j.jeurceramsoc.2015.11.034.

[26]J. Baber, A. Klimera, F. Raether, In situ measurement of dimensional changes and temperature fields during sintering with a novel thermooptical measuring device, J. Eur. Ceram. Soc. 27 (2007) 701-705. doi:10.1016/j.jeurceramsoc.2006.04.043. [27]E.B. Slamovich, F.F. Lange, Densification of Large Pores: I, Expriments, J. Am. Ceram. Soc. 75 (1992) 2498-2508. doi:10.1111/j.1151-2916.1992.tb05603.x. 
[28]W.D. Kingery, B. Francois, The sintering of crystalline oxides: I, Interaction between grain boundaries and pores, in: G.C. Kuczynski, N.A. Hooton and C.F. Gibbon (Eds.), Sintering and related phenomena, Gordan and Breach, New York, 1967, pp. 471-96.

[29]T. Fujiu, G.L. Messing, Sintering of foamed silica gels, J. Non. Cryst. Solids. 143 (1992) 133-139. doi:10.1016/S0022-3093(05)80560-5.

[30]C.C. Wei, O.Y. Chen, Y. Liu, K. Li, Ceramic asymmetric hollow fibre membranes-One step fabrication process, J. Memb. Sci. 320 (2008) 191-197. doi:10.1016/j.memsci.2008.04.003.

[31]C. Ren, H. Fang, J. Gu, L. Winnubst, C. Chen, Preparation and characterization of hydrophobic alumina planar membranes for water desalination, J. Eur. Ceram. Soc. 35 (2015) 723-730. doi:10.1016/j.jeurceramsoc.2014.07.012.

[32] W. Fang, J. Gao, C. Chen, $\mathrm{La}_{0.8} \mathrm{Sr}_{0.2} \mathrm{Cr}_{0.5} \mathrm{Fe}_{0.5} \mathrm{O}_{3-\delta}(\mathrm{LSCF})-\mathrm{Zr}_{0.8} \mathrm{Y}_{0.2} \mathrm{O}_{2-\delta}$ (YSZ) based multilayer membrane for $\mathrm{CO}_{2}$ decomposition, Ceram. Int. 39 (2013) 72697272. doi:10.1016/j.ceramint.2013.02.018.

[33]L.C. De Jonghe, M.N. Rahaman, Sintering of ceramics, in: S.Sōmiya (Eds.), Handbook of advanced ceramics, Elsevier, New York, 2003, pp. 197-264.

[34]H.L. Frandsen, E. Olevsky, T.T. Molla, V. Esposito, R. Bjørk, N. Pryds, Modeling sintering of multilayers under influence of gravity, J. Am. Ceram. Soc. 96 (2013) 80-89. doi:10.1111/jace.12070.

[35]T.T. Molla, H.L. Frandsen, R. Bjørk, D.W. Ni, E. Olevsky, N. Pryds, Modeling kinetics of distortion in porous bi-layered structures, J. Eur. Ceram. Soc. 33 (2013) 
1297-1305. doi:10.1016/j.jeurceramsoc.2012.12.019.

[36]R. Zuo, J. Rödel, Temperature dependence of constitutive behaviour for solidstate sintering of alumina, Acta Mater. 52 (2004) 3059-3067.

doi:10.1016/j.actamat.2004.03.008.

[37]E.A. Olevsky, Theory of sintering: from discrete to continuum, Mater. Sci. Eng. R Reports. 23 (1998) 41-100. doi:10.1016/S0927-796X(98)00009-6.

[38]R. Zuo, E. Aulbach, J. Rödel, Experimental determination of sintering stresses and sintering viscosities, Acta Mater. 51 (2003) 4563-4574. doi:10.1016/S13596454(03)00293-3.

[39]J.B. Austin, Thermal expansion of nonmetallic crystals, J. Am. Ceram. Soc. 35 (1923) 243-253. doi:10.1111/j.1151-2916.1952.tb13042.x.

[40]K. Kwok, P.S. Jørgensen, H.L. Frandsen, Computation of Effective Steady-State Creep of Porous Ni-YSZ Composites with Reconstructed Microstructures, J. Am. Ceram. Soc. 98 (2015) 2873-2880. doi:10.1111/jace.13712. 